\title{
Exploring the boundaries of Bariatric Surgery
}

Citation for published version (APA):

Paulus, G. F. (2021). Exploring the boundaries of Bariatric Surgery: Should we introduce it to adolescents and can we innovate traditional surgery? [Doctoral Thesis, Maastricht University]. Maastricht University. https://doi.org/10.26481/dis.20210416gp

Document status and date:

Published: 01/01/2021

DOI:

10.26481/dis.20210416gp

Document Version:

Publisher's PDF, also known as Version of record

\section{Please check the document version of this publication:}

- A submitted manuscript is the version of the article upon submission and before peer-review. There can be important differences between the submitted version and the official published version of record.

People interested in the research are advised to contact the author for the final version of the publication, or visit the DOI to the publisher's website.

- The final author version and the galley proof are versions of the publication after peer review.

- The final published version features the final layout of the paper including the volume, issue and page numbers.

Link to publication

\footnotetext{
General rights rights.

- You may freely distribute the URL identifying the publication in the public portal. please follow below link for the End User Agreement:

www.umlib.nl/taverne-license

Take down policy

If you believe that this document breaches copyright please contact us at:

repository@maastrichtuniversity.nl

providing details and we will investigate your claim.
}

Copyright and moral rights for the publications made accessible in the public portal are retained by the authors and/or other copyright owners and it is a condition of accessing publications that users recognise and abide by the legal requirements associated with these

- Users may download and print one copy of any publication from the public portal for the purpose of private study or research.

- You may not further distribute the material or use it for any profit-making activity or commercial gain

If the publication is distributed under the terms of Article $25 \mathrm{fa}$ of the Dutch Copyright Act, indicated by the "Taverne" license above, 
Nederlandse

Samenvatting 


\section{ACHTERGROND}

Sinds de eerste studie voor dit proefschrift werd gestart in 2010, is de prevalentie van obesitas alleen maar gestegen. De Wereldgezondheidsorganisatie (Engels: World Health Organisation, WHO) rapporteerde een toename van 25.4\% naar 28.6\% bij volwassenen en van $12.5 \%$ naar $14.4 \%$ bij kinderen en adolescenten in Noord- en Zuid-Amerika. In Nederland is het aantal gevallen van obesitas bij volwassenen gestegen van $17.7 \%$ naar $20.4 \%$ en bij kinderen en adolescenten van 5.9\% naar 7.0\% (1, 2). Vanuit overheid, scholen en gemeenten wordt veel aandacht en geld besteed aan de preventie van overgewicht $(3,4)$. Echter, de toenemende prevalentiecijfers illustreren dat we er ondanks alle inspanningen niet in slagen de obesitas epidemie onder controle te krijgen.

Bariatrische chirurgie is de enige bewezen effectieve behandeling van morbide obesitas op de lange termijn $(5,6)$. Als reactie op de obesitas epidemie is het aantal bariatrische ingrepen per jaar drastisch toegenomen. Zo steeg het aantal ingrepen in de Verenigde Staten van 158.000 in 2011 naar 228.000 in 2017 (7). In Nederland werd het aantal bariatrische ingrepen verdrievoudigd over een periode van 11 jaar; van 3.500 geregistreerde ingrepen in 2007 naar 11.468 in 2018. Naar schatting voldoen echter 350.000 Nederlandse patiënten aan de criteria voor bariatrische chirurgie (8). Innovatieve minimaal invasieve behandelingen zijn steeds meer in opkomst. Uit onderzoek blijkt dat endoscopische bariatrische chirurgie effectiever kan zijn dan dieet- en leefstijlmaatregelen, terwijl het minder invasief is dan traditionele bariatrische chirurgie. De veiligheid en effectiviteit van deze behandelingen wordt momenteel uitvoerig onderzocht (9).

In dit proefschrift hebben we de grenzen van de behandeling van morbide obesitas verkend door de toepasbaarheid van bariatrische chirurgie bij adolescenten te bestuderen en vernieuwende bariatrische technieken als behandelmethode te introduceren. 


\section{BARIATRISCHE CHIRURGIE BIJ KINDEREN EN ADOLESCENTEN}

In haar nieuwste richtlijn raadt de Amerikaanse vereniging voor bariatrische chirurgie (ASMBS) aan om bariatrische chirurgie in te zetten voor morbide obese adolescen-ten (10). Hoewel er veelbelovende onderzoeksresultaten zijn, mag dat advies als voorbarig worden beschouwd. In Hoofdstuk 2 wordt een meta-analyse gepresenteerd over bariatrische chirurgie bij patiënten jonger dan 18 jaar. Uit de resultaten van 538 laparoscopisch geplaatste maagbanden, 495 gastric bypasses (maagomleidingen) en 272 laparoscopische maagverkleiningen blijkt dat alle drie de procedures tot substantieel gewichtsverlies op de korte en middellange termijn leiden. We concluderen dat chirurgische interventies voor de behandeling van obesitas toepasbaar zijn bij zorgvuldig geselecteerde adolescenten, mede gezien het relatief beperkte aantal complicaties. Bovendien was de afname van aan obesitas gerelateerde ziekten (zogenaamde comorbiditeit) indrukwekkend na alle drie de behandeltechnieken. Er moet echter benadrukt worden dat de beschikbare literatuur van matige kwaliteit is, waarbij de meeste studies observationeel en heterogeen zijn. Desondanks trok de ASMBS zijn conclusies vrijwel volledig op basis van onze analyse, gepaard met een lange-termijn studie van Thomas Inge in 2017 over gastric bypass chirurgie, waarin de bovengrens van adolescentie niet 18 , maar 21 jaar was (11).

Hoofdstuk 3 van dit proefschrift bestaat uit een retrospectieve analyse van 10 adolescenten (jonger dan 18 jaar) die een maagband kregen. Uit onze resultaten bleek dat 6 van de 10 patiënten meer dan 50\% van hun overgewicht kwijtraakten, maar dat het meeste gewicht werd verloren na het eerste postoperatieve jaar. De meeste complicaties traden op na drie jaar, overeenkomstig met wat andere wetenschappers constateerden (12). Bij de patiënten waarbij een maagband faalde, kon er succesvol worden geconverteerd naar een andere procedure. De aanbevelingen uit de richtlijn van de ASMBS uit 2018 zorgen er mogelijk voor dat bariatrische chirurgie bij adolescenten wordt aangeboden als reguliere zorg, waardoor het wordt teruggetrokken uit de onderzoeksomgeving waarin we ons gegeven de huidige stand van de wetenschap nog steeds zouden moeten begeven. Bovendien worden alleen de maagverkleining en de gastric bypass als eerste keuze aanbevolen, terwijl de maagband het laagste perioperatieve risico kent en effectief blijkt voor de meeste patiënten (Hoofdstuk 2 en Hoofdstuk 3).

Wij zijn ervan overtuigd dat goed ontworpen studies, bij voorkeur gerandomiseerd en met een controlegroep, nog steeds nodig zijn om de gevolgen van bariatrische chirurgie op jonge leeftijd te ontrafelen. Om die reden zijn we de BASIC-trial (Bariatric Sur- 
gery in Children) gestart, waarvan het protocol in Hoofdstuk 4 wordt gepresenteerd. De BASIC-trial is een studie naar de effecten van een maagbandoperatie bij morbide obese adolescenten, waarbij gecombineerde leefstijlinterventie (GLI) heeft gefaald. We streven naar het leveren van hoogwaardig bewijs met betrekking tot gewichtsverlies, veiligheid, afname van comorbiditeit, psychosociaal welbevinden en eetgedrag. Bij zestig adolescenten in de leeftijd van 14 t/m 16 jaar werd door middel van randomisatie bepaald of een maagbandoperatie werd toegevoegd aan GLI. De laatste patiënten werden eind 2018 opgenomen in het onderzoek. Na 1 jaar follow-up, zullen de resultaten worden gepubliceerd in 2021. Op basis van eerder verricht onderzoek verwachten we significante verschillen in gewichtsverlies en afname van comorbiditeit, met een acceptabel percentage complicaties en positieve effecten op persoonlijkheid en eetgedrag. Bovendien zal deze studie inzicht geven in de ontwikkeling van niet-alcoholische leververvetting, cardiovasculaire veranderingen, slaappatroon, inflammatoire status, metabole en endocriene processen en zullen verschillen tussen beide behandelgroepen aan het licht komen.

\section{ENDOSCOPISCH PLOOIEN VAN DE MAAG}

In Hoofdstuk $\mathbf{5}$ worden de resultaten van een multicenter studie gepresenteerd. In deze studie werd voor het eerst bij de mens gedemonstreerd dat endoscopische gastroplicatie met de Articulating Circular Endoscopic (ACE) stapler technisch haalbaar en veilig is. Door de maag te plooien wordt het volume verkleind (Afbeelding 1). Honderdzestig gastroplicaties werden gecreëerd bij 17 patiënten zonder significante problemen, terwijl het gewichtsverlies bemoedigend was.

Een van de grootste pluspunten van deze techniek is dat over de volledige dikte van de maagwand plooien worden gemaakt, waarbij serosa (buitenwand) tegen serosa komt te liggen. Het voordeel hiervan is dat de serosa kan vergroeien. Bij andere vernieuwende endoluminale technieken, zoals de verticale gastroplastiek (EVG) en transorale gastroplastiek (TOGA, Afbeelding 2), wordt mucosa (binnenwand) tegen mucosa gehecht. Bij endoscopische controle tijdens follow-up bleek dat veel van de nietjes of hechtingen los lieten $(14,15)$. In tegenstelling tot die bevindingen, blijven de plooien een jaar na endoscopische gastroplicatie met de ACE stapler wel behouden.

Om meer inzicht te krijgen in de manier waarop gastroplicatie van de maag tot gewichtsverlies leidt, hebben we meerdere aanvullende studies uitgevoerd. Gedurende een aantal testdagen verzamelden we bloedmonsters en vragenlijsten, patiënten voerden computertaken uit en we namen weefsel af uit de fundus van de maag, het antrum 

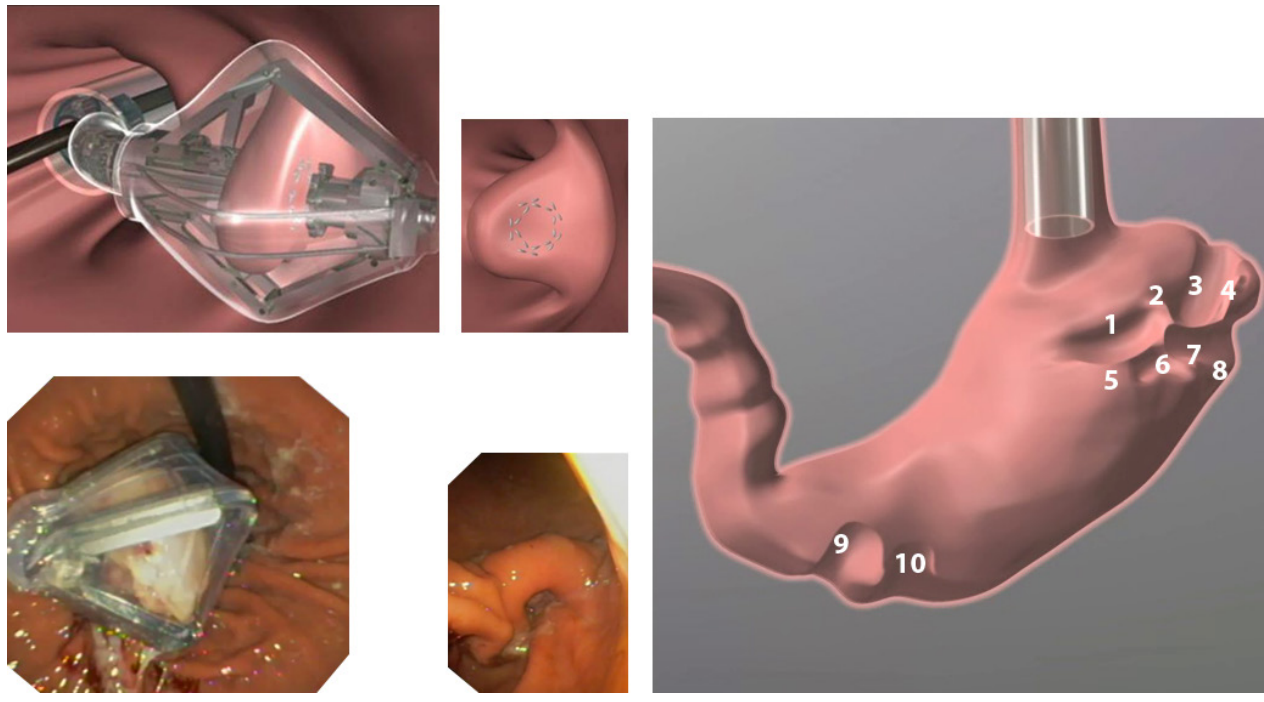

Afbeelding 1 1 ACE stapling techniek

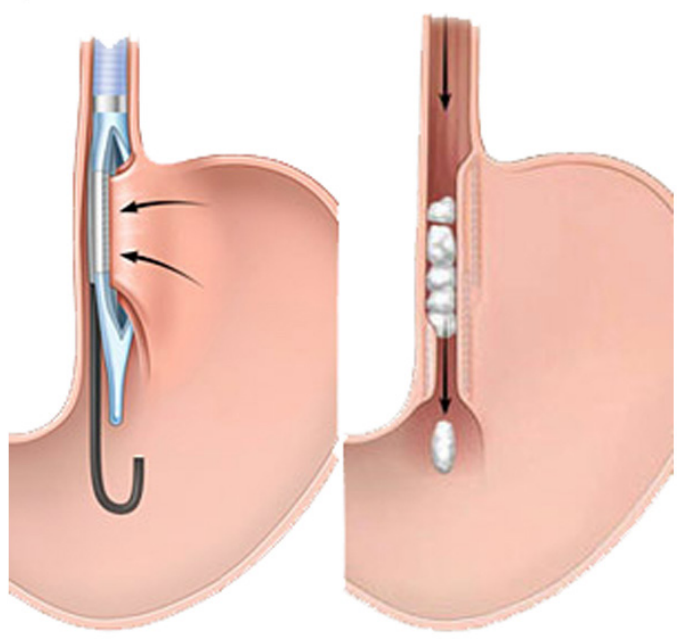

Afbeelding 2 | TOGA procedure 
en het duodenum. De resultaten van deze studies toonden interessante veranderingen in gevoelens van honger en verzadiging, vrijwillige calorie inname, hormonale reacties, gen- en enzymexpressie, eetgedrag en de belonende waarde van voedsel.

In Hoofdstuk 6 laten we zien dat honger en verzadiging, vrijwillige calorie inname en de afgifte van de gastro-intestinale hormonen ghreline, glucagon-like-peptide-1 (GLP-1) en peptide YY (PYY) veranderen. We ontdekten dat het plooien van de maag resulteerde in afname van het hongergevoel en toename van verzadiging, gepaard gaande met een 50\% afname van ad libitum (vrijwillige) voedselinname.

Ghreline is een honger bevorderend hormoon, met name afkomstig uit de maag, dat geassocieerd is met voedingsstatus: het neemt gestaag toe na een periode van vasten en daalt snel na de inname van voedsel (17). We constateerden dan ook dat het nuchter ghreline verhoogd was na gastroplicatie. Een daling van het plasma ghreline zagen we alleen na gastroplicatie en daarvoor helemaal niet. Het is aannemelijk dat inname van een relatief klein ontbijt significante rek veroorzaakt op de mechanosensitieve receptoren van de geplooide maag, terwijl het volume van datzelfde ontbijt te klein was om een soortgelijke reactie uit te lokken in de grotere, ongeplooide maag.

Bovendien zagen we een maand na de procedure een afname in de nuchtere spiegels van de honger remmende hormonen PYY en GLP-1. Deze compensatoire hormonale reactie om voedselinname te bevorderen en terug te komen op een stabiel lichaamsgewicht wordt waarschijnlijk veroorzaakt door het gewichtsverlies. Dit effect werd ook door andere onderzoekers na een vergelijkbare behandeling geconstateerd (21). Een interessante bevinding is echter dat nuchtere PYY en GLP-1 spiegels na een jaar juist verhoogd waren in plaats van verlaagd, wat zou kunnen duiden op het bereiken van een nieuw 'set-point', leidend tot een sterker verzadigingssignaal en daarmee een bijdrage leverend voor een stabiel of zelfs verder afnemend gewicht.

Het experiment dat in Hoofdstuk 7 wordt gepresenteerd, evalueert hoe patiënten de belonende waarde van eten voor en na de ingreep ervaren. 'Liking' van etensmiddelen was verminderd na de procedure, terwijl 'wanting' onveranderd bleef; een effect dat opgemerkt werd in zowel de nuchtere als de verzadigde staat. We constateerden ook dat het effect van een maaltijd op 'liking' van brood en broodbeleg veranderd was, waaruit we kunnen afleiden dat er verminderde aandacht is voor eten bij verzadigde patiënten na gastroplicatie. Dit verschil werd pas na 12 maanden waargenomen. De Three-Factor Eating Questionnaire (TFEQ) werd gebruikt om eetgedrag te evalueren. Patiënten ervoeren minder ongecontroleerd eetgedrag nadat hun maag geplooid was. Daarnaast hadden patiënten een positiever zelfbeeld na behandeling met de ACE stapling techniek, zoals duidelijk werd middels de Eating Disorder Examination Questionnaire (EDE-Q). 
In Hoofdstuk 8 hebben we een jaar na de gastroplicatie plasma en weefselveranderingen bestudeerd. We observeerden een stijging in het plasma adiponectine en afname van $\mathrm{HbA1c}$, waarvan bekend is dat dit veroorzaakt wordt door verlies van overmatig lichaamsvet (28-31). Deze bevindingen zijn in lijn met de verminderde behoefte aan diabetes medicatie, wat we reeds in Hoofdstuk 5 hebben aangetoond.

Een interessante observatie was dat de gemiddelde genexpressie van ghreline en het enzym GOAT (verantwoordelijk voor de acetylering van ghreline) in het weefsel van de fundus afnam na gastroplicatie. Tegelijkertijd was het plasma ghreline juist verhoogd (Hoofdstuk 6), waarbij een positieve correlatie blijkt te bestaan tussen de genexpressie in het weefsel en de plasmawaarden. Dit houdt in dat toegenomen expressie van ghreline in de fundus geassocieerd was met een toename van nuchter ghreline terwijl verminderde expressie van ghreline zorgde voor een kleinere toename van nuchter ghreline in het plasma. De implicaties van deze veranderingen worden nog niet volledig begrepen en moeten verder worden onderzocht.

Daarnaast hebben we voor het eerst veranderingen in het volledige transcriptoom van proximaal maag- en darmweefsel geanalyseerd na een bariatrische ingreep. Deze analyses toonden downregulatie van inflammatoire activiteit in weefsel van de fundus van de maag en het duodenum. Verminderde spiegels van inflammatoire markers in plasma worden over het algemeen gezien als een gevolg van de afname van viscerale vetmassa, wat een belangrijke rol speelt in de laaggradige inflammatoire status die geassocieerd wordt met obesitas (32). Er bestaat dan ook toenemend bewijs dat er een link is tussen intestinale inflammatiestatus, obesitas en diabetes (33-36). Op basis van de huidige onderzoeksresultaten kunnen we niet vaststellen of de gebleken afname van inflammatoire tonus in het proximale maagdarmkanaal een voornamelijk lokale oorzaak heeft, door een veranderd voedselinname patroon of verteringsproces, of dat het een afspiegeling is van verminderde laaggradige systemische inflammatie op basis van de afname van lichaamsvetmassa.

In het antrum van de maag was de expressie verhoogd van genen die gerelateerd zijn aan de celcyclus en de opbouw van extracellulaire matrix. Dit zou verklaard kunnen worden door de geleidelijke dilatatie van de maag, een gebruikelijke bevinding na volumereductie van de maag (37-40). Hoewel het maagvolume niet gekwantificeerd werd in onze studie, imponeerde de maag tijdens de endoscopie een jaar na gastroplicatie groter dan meteen na de ingreep.

Concluderend hebben we in Hoofdstuk 5 t/m 8 aangetoond dat endoscopische gastroplicatie veilig is en dat het leidt tot verminderde gevoelens van honger en toename van verzadiging, gevolgd door verminderde vrijwillige voedselinname en significant gewichtsverlies in het eerste jaar. Deze veranderingen gaan gepaard met voordelige 
veranderingen in gastro-intestinale hormoonreacties, ondanks een onveranderde maagontledigingssnelheid. Patiënten ervoeren minder ongecontroleerd eetgedrag en verminderde 'liking' van eten nadat ze behandeld waren. Het glucosemetabolisme verbeterde, wat werd aangetoond door afname van het HbA1c en verminderde noodzaak tot het nemen van diabetes medicatie. Deze studies hebben inzicht gegeven in het werkingsmechanisme van endoscopische gastroplicatie. We toonden hierbij aan dat de meeste effecten sterker waren na 1 maand dan na 12 maanden follow-up. Chronisch overeten zou rek op de maagwand kunnen veroorzaken waardoor de proximale maag weer uitrekt - een theorie die ondersteund wordt door verhoogde celcyclus activiteit in het antrum van de maag - en het effect afneemt. Dit verschijnsel is vergelijkbaar met dilatatie van de pouch na gastric bypass chirurgie (41). Het uitbreiden van de follow-up duur in toekomstige studies zou opheldering kunnen geven over de mate waarin het effect afneemt. Daarnaast stellen we voor additionele plicaties te creëren bij patiënten die aankomen in gewicht of kampen met toename van hongergevoel een jaar na gastroplicatie.

\section{ELEKTRISCHE STIMULATIE VAN DE MAAG MET HET EXILIS ${ }^{\text {TM }}$ SYSTEEM}

Een andere vernieuwende bariatrisch chirurgische techniek is de maagstimulator (gastro-elekrische stimulatie, GES). Een elektrische stimulator wordt onderhuids geïmplanteerd en laparoscopisch verbonden met de maagwand middels twee draden. Dit is een anatomiebehoudende techniek, waarbij beoogd wordt zowel de motorische functie van de maag als verzadigingsgevoelens te beïnvloeden. Hierdoor wordt voedselinname geremd, wat leidt tot gewichtsverlies. Verscheidene GES-systemen zijn ontwikkeld en onderzocht in de laatste decennia. De initiële resultaten met de Transcend stimulator waren veelbelovend, maar er werd geen duidelijk positief effect op gewicht geconstateerd in vergelijking met een groep die nep-stimulatie kreeg in verschillende dubbelblind gerandomiseerde studies (42-44). In een periode van vijf jaar werd uitgebreid dieronderzoek verricht, waarbij de specificaties die nodig zijn voor optimale GES opnieuw werden gedefinieerd (45). Dit heeft geleid tot de ontwikkeling van het huidige Exilis ${ }^{\mathrm{TM}}$ systeem.

In Hoofdstuk 9, onderzochten we de veiligheid en haalbaarheid van dit systeem voor het eerst in de mens. Daarnaast werd gekeken naar het effect van deze methode bij 20 patiënten. Hoewel de procedure technisch uitvoerbaar en veilig bleek, zijn we er niet in geslaagd bewijs te leveren voor een voordelig effect. Noch de motorische 
functie van de maag, noch verzadiging of ad libitum voedselinname waren significant veranderd. Na een jaar was het gewicht niet significant verminderd ten opzichte van de baseline. Er werd enkel een significante verbetering in kwaliteit van leven gerapporteerd. We hebben geen verklaring kunnen vinden voor de discrepantie in resultaten tussen dieren en mensen. Het ontstaan van obesitas is multifactorieel en veel psychologische en fysiologische systemen zijn betrokken bij gewichtsverlies, zoals ook werd aangetoond met de uitgebreide studies die we in het het kader van de ACE stapler hebben gedaan. Bovendien ontbreekt essentiële elektrofysiologische kennis van de menselijke maag. Ons inziens zal er meer kennis over basale elektrofysiologische processen opgedaan moeten worden, voordat er verder wordt gekeken naar de mogelijkheden van nieuwe maagstimulatieprotocollen. Vervolgens kan door middel van high-resolution mapping van activiteit in de maag worden onderzocht of bepaalde instellingen effectief zullen zijn (47). Wanneer optimale stimulatie parameters vastgesteld zijn, raden we aan deze te onderzoeken in een geblindeerd placebogecontroleerde studie.

\section{CONCLUSIES EN TOEKOMSTPERSPECTIEF}

Er is momenteel meer wetenschappelijk onderzoek gaande naar het ontstaan en de behandeling van morbide obesitas dan ooit tevoren. De gastric bypass en de maagverkleining hebben een prominente plaats in de behandeling van morbide obese patiënten. Echter, er kunnen zeer valide redenen zijn om patiënten niet bloot te stellen aan deze onomkeerbare, anatomie veranderende procedure met potentieel ernstige complicaties. Hoewel we geloven dat er een plaats is voor bariatrische chirurgie in de behandeling van adolescente patiënten, moet selectie met grote zorgvuldigheid plaatvinden in een transparante onderzoeksomgeving. Het is te vroeg om bariatrische chirurgie naar de standaardpraktijk te brengen, zoals gesuggereerd wordt door de ASMBS. Zelfs wanneer we aannemen dat bariatrische chirurgie veilig is en leidt tot gewichtsverlies, weten we nog te weinig over de ontwikkeling van fysieke en mentale comorbiditeit bij adolescenten. Om die reden zijn gerandomiseerde studies zoals de BASIC-trial van groot belang.

Ondanks het toenemende aantal uitgevoerde bariatrische procedures wereldwijd, ondergaat slechts een klein percentage van de morbide obese populatie bariatrische chirurgie. De reden daarvoor is meerledig en bestaat onder andere uit kosten, beschikbaarheid en angst voor complicaties. Nieuwe, minimaal invasieve en/of compleet omkeerbare procedures kunnen deze problemen wellicht oplossen en uitkomst bieden 
voor diegenen die nu buiten de boot vallen. Procedures die worden toegepast in de praktijk of worden onderzocht variëren van ruimte-innemende hulpmiddelen zoals de maagballon tot endoscopische staple- of hechttechnieken, van malabsorptieve technieken, zoals de EndoBarrier tot botuline toxine injecties en van maagstimulatoren tot vagusblokkade (48). Zelfs als er minder gewichtsverlies behaald wordt dan met traditionele invasieve procedures, moeten we deze technieken blijven ontwikkelen en bestuderen. Als de resultaten namelijk dicht genoeg in de buurt komen is er een enorme populatie die hiervan kan profiteren vanwege het lage complicatierisico. Al met al, lijkt er een toekomst weggelegd voor de behandeling van morbide obesitas door middel van enkele minimaal invasieve technieken. We hebben aangetoond dat endoscopische gastroplicatie, maar niet gastro-elektrische stimulatie in zijn huidige vorm, kan leiden tot blijvend gewichtsverlies, afname van comorbiditeit, fysiologische veranderingen en gedragsveranderingen. 


\section{REFERENTIES}

1. WHO. Prevalence of obesity among adults 2017 [Available from: http://apps.who.int/gho/ data/view.main.REGION2480A?lang=en.

2. WHO. Prevalence of obesity among children and adolescents 2017 [Available from: http://apps.who.int/gho/data/view.main. BMIPLUS2REGv?lang=en.

3. Rijksoverheid. Overgewicht terugdringen 2018 [Available from: https://www.rijksoverheid. nl/onderwerpen/overgewicht/overgewichtterugdringen.

4. Agriculture UNIoFa. Obesity Prevention \& Healthy Weight Programs 2018 [Available from: https://nifa.usda.gov/program/obesityprevention-healthy-weight-programs.

5. Jensen MD, Ryan DH, Apovian CM, Ard JD, Comuzzie AG, Donato KA, et al. 2013 AHA/ ACC/TOS guideline for the management of overweight and obesity in adults: a report of the American College of Cardiology/American Heart Association Task Force on Practice Guidelines and The Obesity Society. Journal of the American College of Cardiology. 2014;63(25 Pt B):2985-3023.

6. Courcoulas AP, Christian NJ, Belle SH, Berk PD, Flum DR, Garcia L, et al. Weight Change and Health Outcomes at 3 Years After Bariatric Surgery Among Individuals With Severe Obesity. JAMA. 2013.

7. ASMBS. Estimate of Bariatric Surgery Numbers, 2011-2017 2018 [Available from: https://asmbs.org/resources/estimate-ofbariatric-surgery-numbers.

8. CZ. Verantwoordingsdocument Bariatrie 2018 [Available from: https://www.cz.nl/-/media/ zorgaanbieder/2018/zorginkoopbeleid/ verantwoordingsdocument-selectieve-inkoopbariatrie.pdf.

9. Kumar N. Weight loss endoscopy: Development, applications, and current status. World Journal of Gastroenterology. 2016;22(31):7069.

10. Pratt JSASA, Browne A, Browne NT, Bruzoni $M$, Cohen $M$, Desai A, et al. ASMBS pediatric metabolic and bariatric surgery guidelines, 2018. Surgery for obesity and related diseases
: official journal of the American Society for Bariatric Surgery. 2018;14(7):882-901.

11. Inge $\mathrm{TH}$, Jenkins TM, Xanthakos SA, Dixon JB, Daniels SR, Zeller MH, et al. Long-term outcomes of bariatric surgery in adolescents with severe obesity (FABS-5+): a prospective follow-up analysis. The Lancet Diabetes \& Endocrinology. 2017;5(3):165-73.

12. Silberhumer GR, Miller K, Pump A, Kriwanek S, Widhalm K, Gyoeri G, et al. Long-term results after laparoscopic adjustable gastric banding in adolescent patients: follow-up of the Austrian experience. Surg Endosc. 2011;25(9):2993-9.

13. Coblijn UK, Verveld CJ, van Wagensveld BA, Lagarde SM. Laparoscopic Roux-en-Y gastric bypass or laparoscopic sleeve gastrectomy as revisional procedure after adjustable gastric band--a systematic review. Obesity surgery. 2013;23(11):1899-914.

14. Familiari P, Costamagna $G$, Bléro $D$, Le Moine O, Perri V, Boskoski I, et al. Transoral gastroplasty for morbid obesity: a multicenter trial with a 1-year outcome. Gastrointestinal endoscopy. 2011;74(6):1248-58.

15. Fogel R, De Fogel J, Bonilla Y, De La Fuente R. Clinical experience of transoral suturing for an endoluminal vertical gastroplasty: 1-year follow-up in 64 patients. Gastrointestinal endoscopy. 2008;68(1):51-8.

16. Espinos JC, Turro R, Moragas G, Bronstone A, Buchwald JN, Mearin F, et al. Gastrointestinal Physiological Changes and Their Relationship to Weight Loss Following the POSE Procedure. Obesity surgery. 2016;26(5):1081-9.

17. Natalucci G, RiedI S, Gleiss A, Zidek T, Frisch $H$. Spontaneous 24-h ghrelin secretion pattern in fasting subjects: maintenance of a meal-related pattern. European journal of endocrinology / European Federation of Endocrine Societies. 2005;152(6):845-50.

18. Cummings DE, Weigle DS, Frayo RS, Breen PA, Ma MK, Dellinger EP, et al. Plasma ghrelin levels after diet-induced weight loss or gastric bypass surgery. The New England journal of medicine. 2002;346(21):1623-30.

19. Purnell JQ, Cummings D, Weigle DS. Changes in 24-h area-under-the-curve ghrelin values following diet-induced weight loss are associated with loss of fat-free mass, but 
not with changes in fat mass, insulin levels or insulin sensitivity. International journal of obesity (2005). 2007;31(2):385-9.

20. Korner J, Inabnet W, Febres G, Conwell IM, McMahon DJ, Salas R, et al. Prospective study of gut hormone and metabolic changes after adjustable gastric banding and Roux-en-Y gastric bypass. International journal of obesity (2005). 2009;33(7):786-95.

21. Espinós JC, Turró R, Moragas G, Bronstone A, Buchwald JN, Mearin F, et al. Gastrointestinal Physiological Changes and Their Relationship to Weight Loss Following the POSE Procedure. Obesity Surgery. 2016;26(5):1081-9.

22. Behary P, Miras AD. Brain responses to food and weight loss. Experimental physiology. 2014;99(9):1121-7.

23. Frank S, Heinze JM, Fritsche A, Linder $K$, von Feilitzsch M, Königsrainer A, et al. Neuronal Food Reward Activity in Patients With Type 2 Diabetes With Improved Glycemic Control After Bariatric Surgery. Diabetes care. 2016;39(8):1311-7.

24. Born JM, Lemmens SG, Martens MJ, Formisano E, Goebel R, Westerterp-Plantenga MS. Differences between liking and wanting signals in the human brain and relations with cognitive dietary restraint and body mass index. The American journal of clinical nutrition. 2011;94(2):392-403.

25. Drummen MD, E.; Vreugdenhil, A.; Raben, A.; Westerterp-Plantenga, M.S.; Adam T. Changes in brain reactivity to food cues after weight loss and increased protein intake - a PREVIEW Study. AJCN 2018;(in press).

26. Laurenius A, Larsson I, Bueter M, Melanson $\mathrm{KJ}$, Bosaeus I, Forslund HB, et al. Changes in eating behaviour and meal pattern following Roux-en-Y gastric bypass. International journal of obesity (2005). 2012;36(3):348-55.

27. Abu Dayyeh BK, Jirapinyo P, Thompson CC. Plasma Ghrelin Levels and Weight Regain After Roux-en-Y Gastric Bypass Surgery. Obesity surgery. 2017;27(4):1031-6.

28. Yang WS, Lee WJ, Funahashi T, Tanaka S, Matsuzawa Y, Chao CL, et al. Weight reduction increases plasma levels of an adipose-derived anti-inflammatory protein, adiponectin. J Clin Endocrinol Metab. 2001;86(8):3815-9.

29. Lang HF, Chou CY, Sheu WH, Lin JY. Weight loss increased serum adiponectin but decreased lipid levels in obese subjects whose body mass index was lower than $30 \mathrm{~kg} / \mathrm{m}(2)$. Nutr Res. 2011;31(5):378-86.

30. Penn L, White M, Lindstrom J, den Boer AT, Blaak E, Eriksson JG, et al. Importance of weight loss maintenance and risk prediction in the prevention of type 2 diabetes: analysis of European Diabetes Prevention Study RCT. PLoS ONE. 2013;8(2):e57143.

31. Baskota A, Li S, Dhakal N, Liu G, Tian H. Bariatric Surgery for Type 2 Diabetes Mellitus in Patients with BMI $<30$ kg/m2: A Systematic Review and Meta-Analysis. PLoS ONE. 2015;10(7):e0132335.

32. Ghigliotti G, Barisione C, Garibaldi S, Fabbi P, Brunelli C, Spallarossa P, et al. Adipose tissue immune response: novel triggers and consequences for chronic inflammatory conditions. Inflammation. 2014;37(4):1337-53.

33. Monteiro-Sepulveda M, Touch S, Mendes-Sa C, Andre S, Poitou C, Allatif O, et al. Jejunal T Cell Inflammation in Human Obesity Correlates with Decreased Enterocyte Insulin Signaling. Cell Metab. 2015;22(1):113-24.

34. Pendyala S, Neff LM, Suarez-Farinas $M$, Holt PR. Diet-induced weight loss reduces colorectal inflammation: implications for colorectal carcinogenesis. Am J Clin Nutr. 2011;93(2):234-42.

35. Veilleux A, Mayeur S, Berube JC, Beaulieu JF, Tremblay E, Hould FS, et al. Altered intestinal functions and increased local inflammation in insulin-resistant obese subjects: a gene-expression profile analysis. BMC Gastroenterol. 2015;15:119.

36. Veilleux A, Grenier E, Marceau P, Carpentier AC, Richard D, Levy E. Intestinal lipid handling: evidence and implication of insulin signaling abnormalities in human obese subjects. Arterioscler Thromb Vasc Biol. 2014;34(3):64453.

37. Safatle-Ribeiro AV, Petersen PA, Pereira Filho DS, Corbett CE, Faintuch J, Ishida R, et al. Epithelial cell turnover is increased in the excluded stomach mucosa after Roux-en-Y gastric bypass for morbid obesity. Obes Surg. 2013;23(10):1616-23.

38. Iannelli A, Schneck AS, Hebuterne X, Gugenheim J. Gastric pouch resizing for 
Roux-en-Y gastric bypass failure in patients with a dilated pouch. Surg Obes Relat Dis. 2013;9(2):260-7.

39. van Wezenbeek MR, Smulders JF, de Zoete JP, Luyer MD, van Montfort G, Nienhuijs SW. Long-Term Results of Primary Vertical Banded Gastroplasty. Obes Surg. 2014.

40. Baumann T, Grueneberger J, Pache G, Kuesters S, Marjanovic G, Kulemann B, et al. Threedimensional stomach analysis with computed tomography after laparoscopic sleeve gastrectomy: sleeve dilation and thoracic migration. Surg Endosc. 2011;25(7):2323-9.

41. Thompson CC, Jacobsen GR, Schroder GL, Horgan S. Stoma size critical to 12-month outcomes in endoscopic suturing for gastric bypass repair. Surgery for obesity and related diseases : official journal of the American Society for Bariatric Surgery. 2012;8(3):282-7.

42. Favretti F, De Luca M, Segato G, Busetto L, Ceoloni A, Magon A, et al. Treatment of morbid obesity with the Transcend Implantable Gastric Stimulator (IGS): a prospective survey. Obesity surgery. 2004;14(5):666-70.

43. Shikora SA. "What are the yanks doing?" the U.S. experience with implantable gastric stimulation (IGS) for the treatment of obesity - update on the ongoing clinical trials. Obesity surgery. 2004;14 Suppl 1:8.

44. Shikora SA, Bergenstal R, Bessler M, Brody F, Foster G, Frank A, et al. Implantable gastric stimulation for the treatment of clinically severe obesity: results of the SHAPE trial. Surg Obes Relat Dis. 2009;5(1):31-7.

45. Song G-QQ, Zhu H, Lei Y, Yuan C, Starkebaum W, Yin J, et al. Gastric electrical stimulation optimized to inhibit gastric motility reduces food intake in dogs. Obesity surgery. 2015;25(6):1047-55.

46. Lammers WJ. Arrhythmias in the gut. Neurogastroenterol Motil. 2013;25(5):353-7.

47. O'Grady G, Du P, Lammers WJ, Egbuji JU, Mithraratne P, Chen JD, et al. High-resolution entrainment mapping of gastric pacing: a new analytical tool. American journal of physiology Gastrointestinal and liver physiology. 2010;298(2):21.

48. Štimac D, Majanovic S, Licina M. Recent Trends in Endoscopic Management of Obesity. Surgical Innovation. 2016;23(5):525-37. 